\title{
Weak Form of Market Efficiency Trading Range Breakout Test on Weekly Stocks of India Markets
}

\author{
Prof. (Dr.) Uttam B. Sapate
}

MM's Institute of Management Education Research and Training, Pune, India

\begin{abstract}
In the financial literature Efficient Market Hypothesis (EMH) has been one of the dominant topics. An implication of weak-form of efficiency / random walk is that the trading rules will not generate economic profits. The purpose of this study is to analyze results of application of trading range breakout (TRB) test on weekly stock prices of Indian Markets, thus investigating its efficiency at the weak form level (Fama,1970). In this study three different strategies viz. Buy, Sell and Buy-Sell of TRB trading rule have been tested on weekly stock prices on 200 stocks from Indian Stock markets over different time periods to test Weak Form of Efficient Market Hypothesis (WFEMH). The results from the TRB trading rule tests indicated that the technical trading rules do not yield statistically significant forecasting power. It means that forecasting of returns based on trading rules cannot be employed to earn abnormal returns.
\end{abstract}

Keywords: Indian Stock Markets, Trading Range Breakout, Trading Rule Test, Weak Form Market Efficiency

\section{INTRODUCTION}

Technical trading systems are composed of sets of trading rules that govern when it is appropriate for a trading to buy or sell their position within an asset. The simple trading strategies that are discussed in this research paper have one or two parameters that offer optimal trade timing by generating buy and sell signals.

According to Fama (1970), in an efficient market, prices "always fully reflect available information". Therefore, prices could be considered an unbiased estimate of the true value of an investment at any given moment. "If stock prices either overreact or under-react to information, then profitable trading strategies that select stocks based on their past returns will exist."

TRB, also known as support and resistance or price channels, are used intensely within technical trading. The underlying concept of price channel trading strategies is that markets that move to new highs or lows suggest continued trends in the established direction. A buy signal is generated in a price channel strategy when the price pierces the resistance level. For price channels the resistance level is defined as the level of the local maximum price. A sell signal is generated, on the other hand, when the price pierces below the support level. Intuitively, the support level is the level of the local minimum price. Technical analysts use these strategies under the belief that traders are willing to sell (buy) at the peak (trough). Therefore, if the price surpasses the extremity of the local maximum (minimum) then it will signal a continuing movement to a new maximum (minimum) that is significant.

The paper is organized as follows; Section 1: Review of literature, Section 2: Data and methodology, Section 3: Analysis and findings, Section 4: Conclusions

\section{LITERATURE REVIEW}

Early academic literature on technical analysis focused upon the profitability of simple technical trading rules such as moving averages and trading range breaks (Fama and Blume, 1966). A major portion of academic literature on technical analysis tested profitability from charting patterns, genetic programming methods, and other technical trading methods. 
Prof. (Dr.) Uttam B. Sapate "Weak Form of Market Efficiency Trading Range Breakout Test on Weekly Stocks of India Markets"

Brock, Lakonishok and LeBaron (1992) investigated two simple technical trading rules viz. variable moving average (VMA) trading rules and trading range breakout rule. They showed that the two simple trading rules have significant predictive power for the United States equity index returns. They defined the moving average trading rules as rules that are implemented by comparing two moving averages calculated over different time periods, one long-run period and the other short-run period. In addition, buy and sell signals are generated by the two different moving average periods. This strategy is expressed as buying (selling) when the short-period moving average rises above (falls below) the long period moving average. The trading range breakout rule generates a buy (sell) signal as the stock price penetrates new highs (lows). They considered the technical trading rule with and without one percent band width. For example, a variable moving average rule for weekly stocks for sub-period of 2.5 years is $(5,50,0.01)$ for which the short period is 5 weeks and the long period is 50 weeks and a $1 \%$ band filter is applied, which indicates that a buy (sell) signal is only produced when the short-run moving average is at least $1 \%$ above (below) the long-run moving average. (Brock et al., 1992).

Trading rules tests of WFEMH based on VMA and TRB were utilized along with other tests by Thomas \& Brian (2005). They carried out test for predictability in seven Middle-Eastern North African markets by investigating both the WFEMH and the returns from technical analysis. Starting with tests for the Random Walk Hypothesis (RWH), they used daily data returns and a battery of econometric tests including unit-root analysis, individual and multiple variance ratio, wild bootstrapping and non-parametric tests based on ranks. Their results suggested that only Israel and Turkey followed a random walk. Technical analysis based on VMA and TRB trade rules constituted further evidence for stock market predictability. Finally, taking into account local trading costs, profit simulations based on the breakeven costs computation methodology established the possibility of raising abnormal positive returns in the region.

\section{DATA AND METHODOLGY}

Data: The data comprises of weekly share prices (adjusted for bonus, rights and stock splits) for 200 companies that form part of the Bombay Stock Exchange (BSE) 200 index from $1^{\text {st }}$ April, 2000 to $31^{\text {st }}$ March, 2010 (weekly observations). The sample companies account for more than $83.6 \%$ of the market capitalization as well as the trading activity on the Indian market. The sample is hence fairly representative of the market performance.

The weekly share price (Friday closing price) series have been converted into weekly return series for further estimation. The weekly data provide 521 observations for ten year period. Subsequently, data was split in to the sub-periods of 5 years and 2.5 years as given below;

Table1. Sub-periods division for data analysis

\begin{tabular}{|c|c|c|c|c|c|c|}
\hline Total 10Yr & $\begin{array}{l}\text { First5Yrsub- } \\
\text { period }\end{array}$ & $\begin{array}{l}\text { Second 5yr } \\
\text { sub-period }\end{array}$ & $\begin{array}{l}\text { First2.5Yr } \\
\text { sub-period }\end{array}$ & $\begin{array}{l}\text { Second 2.5Yr } \\
\text { sub-period }\end{array}$ & $\begin{array}{l}\text { Third 2.5Yr } \\
\text { sub-period }\end{array}$ & $\begin{array}{l}\text { Fourth 2.5Yr } \\
\text { sub-period }\end{array}$ \\
\hline Apr, 00 to Mar, 1 & Apr, 00 to Mar. 05 & Apr. 05 to Mar, 10 & Apr, 00 to Oct, 02 & Oct. O2 to Mar, 05 & Apr, 05 to Oct. 07 & Oct. 07 to Mar, 10 \\
\hline
\end{tabular}

Hypothesis: Ho: 'Buy (Sell, Buy-Sell) strategy' based TRB trading rules in the Indian weekly stock markets return series do not provide significantly different returns than 'buy \& hold strategy'

All the null hypotheses have been tested at $95 \%$ confidence level. Null hypothesis has been rejected if $P$ value is less than 0.05 . 
Prof. (Dr.) Uttam B. Sapate "Weak Form of Market Efficiency Trading Range Breakout Test on Weekly Stocks of India Markets"

Statistical Tools: Initial data processing \& refinement has been done using Microsoft EXCEL. The econometric tests of TRB have been applied using MATLAB software of The MathWorks, Inc. (2008).

Trading Range Breakout Test: The TRB rules generate signals by comparing the current price to the recent minimum and maximum of prices. The TRB rules generate buy signals when the current price exceeds the recent maximum by at least a pre-specified band. The rationale for this rule is that when the current price reaches the previous peak, a great deal of selling pressure arises because many people would like to sell at the peak. However, if the price exceeds the previous peak, it is indicated that the upward trend has been initiated. The purpose of using a band is to avoid the emission of 'spurious' signals. On the other hand, the TRB rules generate sell signals when the current price falls below the recent minimum by at least a pre-specified band. The rational is that when the current price reaches the previous minimum, a great deal of buying pressure arises because many people would like to buy at the minimum price. However, if the price falls below the previous minimum, it is indicated that the downward trend has been initiated. If prices remain in the intermediate range then it maintains the original position. Transaction costs were imputed to the first buy and sell signals. If traders stay out of the market then the return is null. The returns of this active trading rule are compared to a buy and hold strategy.

TRB trading rules are applied on stocks' return series wherein the following price history windows are considered based on maximum number of observations for given type of data set as illustrated.

Table2. Price History Window for TRB test

\begin{tabular}{|l|l|l|l|l|}
\hline $\begin{array}{l}\text { Sr. } \\
\text { No. }\end{array}$ & Frequency of Data & Period of Data & $\begin{array}{l}\text { Maximum No. of } \\
\text { Observations }\end{array}$ & Price History Window \\
\hline $\mathbf{1}$ & Weekly & 10 years & 521 & 80 weeks \\
\hline $\mathbf{2}$ & Weekly & 5 years & 260 & 40 weeks \\
\hline $\mathbf{3}$ & Weekly & 2.5 years & 130 & 20 weeks \\
\hline
\end{tabular}

For application of TRB rules, recent maximums and minimums as the extreme observations over the price history window are found. If absolute value of observed statistics is greater than or equal to critical value then it indicates difference is substantial and rejects that trading rule is not able to generate significant returns than buy and hold strategy in turn rejecting WFEMH.

\section{ANALYSIS AND FINDINGS}

The hypothesis Ho \{'Buy (Sell, Buy-Sell) strategy' based TRB trading rules in the Indian weekly stock markets return series do not provide significantly different returns than 'buy \& hold strategy'.\} is tested using TRB tests.

Table 3 shows the results of TRB tests for weekly log returns of stocks for total ten year period for three strategies. Results of all three TRB strategies with weekly return series accept the null hypothesis in turn accepting Weak Form Market Efficiency Hypothesis. It is observed that for the total period i.e. of 10 years there are no exceptions with regards to TRB test in all strategies in hypothesis acceptance.

Table3. Summary of TRB test for weekly log returns of individual stocks

\begin{tabular}{|l|l|l|l|l|}
\hline Period & Parameter & Buy strategy & Sell strategy & Buy-Sell strategy \\
\hline $\begin{array}{l}\text { April 2000 } \\
\text { March 2010 }\end{array}$ & Acceptance \% & 93.85 & 93.33 & 86.15 \\
\cline { 2 - 5 } & Hypothesis Ho & Accepted & Accepted & Accepted \\
\hline
\end{tabular}

Among the three strategies considered for analysis, the Buy strategy provided highest acceptance at $93.85 \%$ and Buy-Sell strategy provided lowest acceptance at $86.15 \%$ w. r. t. randomness hypothesis in case of weekly data. 
Prof. (Dr.) Uttam B. Sapate "Weak Form of Market Efficiency Trading Range Breakout Test on Weekly Stocks of India Markets"

Table 4 shows the results of TRB Buy Strategy tests for weekly log returns of stocks for all subperiods.

Table4. Sub-period Weekly TRB Buy Strategy test results

\begin{tabular}{|l|l|l|}
\hline Period & Acceptance \% & Hypothesis Ho \\
\hline Total10Yr & 93.85 & Accepted \\
\hline First5Yrsub-period & 97.39 & Accepted \\
\hline Second5Yrsub-period & 96.41 & Accepted \\
\hline First2.5Yrsub-period & $\mathbf{9 8 . 5 8}$ & Accepted \\
\hline Second2.5Yrsub-period & 99.35 & Accepted \\
\hline Third2.5Yrsub-period & $\mathbf{9 7 . 1 9}$ & Accepted \\
\hline Fourth2.5Yrsub-period & $\mathbf{1 0 0 . 0 0}$ & Accepted \\
\hline
\end{tabular}

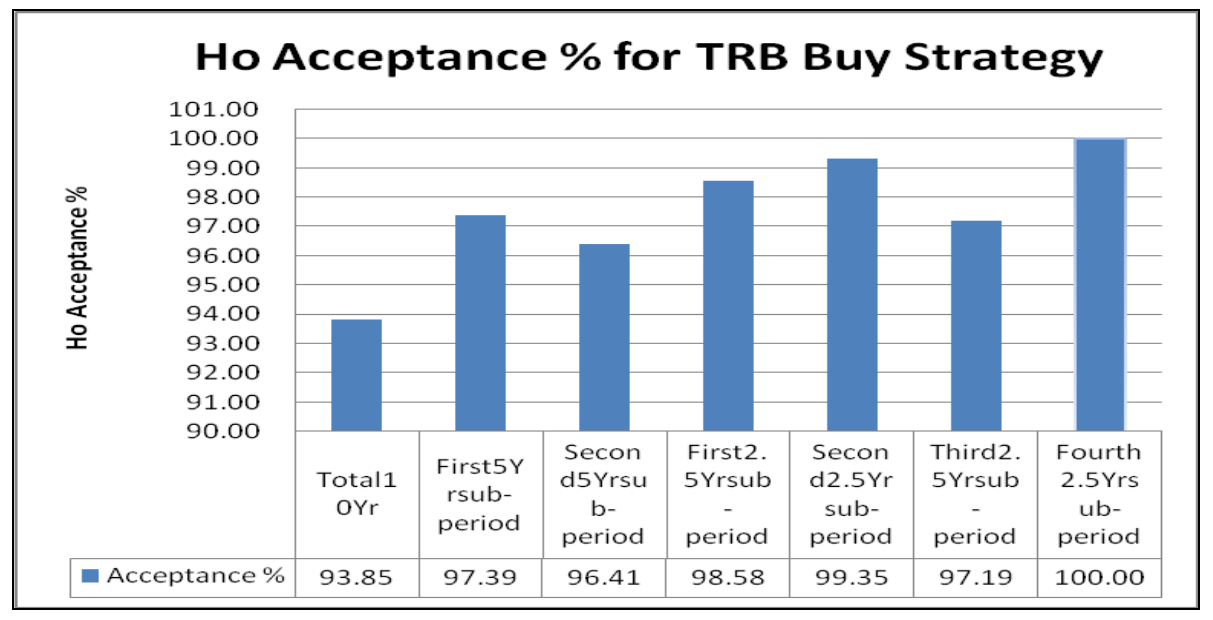

Fig1. Graphical sub-period Weekly TRB Buy Strategy test results

In case of TRB Buy strategy for all seven sub-periods the null hypothesis of weak form of market efficiency is accepted. The acceptance \% is observed to be lowest in case of total 10 year period.

Table 5 shows the results of TRB Sell strategy tests for weekly log returns of stocks for all subperiods.

Table5. Sub-period Weekly TRB Sell Strategy test results

\begin{tabular}{|l|l|l|}
\hline Period & Acceptance \% & Hypothesis Ho \\
\hline Total10Yr & $\mathbf{9 3 . 3 3}$ & Accepted \\
\hline First5Yrsub-period & $\mathbf{9 7 . 3 9}$ & Accepted \\
\hline Second5Yrsub-period & $\mathbf{9 3 . 8 5}$ & Accepted \\
\hline First2.5Yrsub-period & $\mathbf{9 9 . 2 9}$ & Accepted \\
\hline Second2.5Yrsub-period & $\mathbf{9 7 . 3 9}$ & Accepted \\
\hline Third2.5Yrsub-period & $\mathbf{9 8 . 3 1}$ & Accepted \\
\hline Fourth2.5Yrsub-period & $\mathbf{9 8 . 9 7}$ & Accepted \\
\hline
\end{tabular}

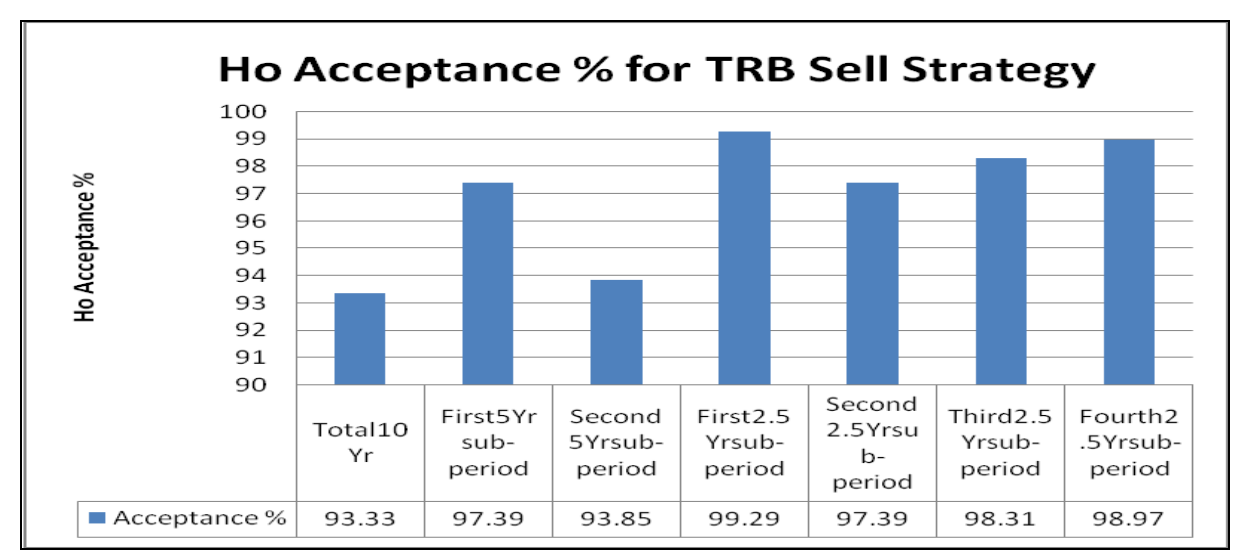

Fig2. Graphical sub-period Weekly TRB Sell Strategy test results 
Prof. (Dr.) Uttam B. Sapate "Weak Form of Market Efficiency Trading Range Breakout Test on Weekly Stocks of India Markets"

In case of TRB Sell strategy for all seven sub-periods the null hypothesis of weak form of market efficiency is accepted. The acceptance \% is observed to be lowest in case of total 10 year period.

Table 6 shows the results of TRB Buy-Sell strategy tests for weekly log returns of stocks for all subperiods.

Table6. Sub-period Weekly TRB Buy-Sell Strategy test results

\begin{tabular}{|l|l|l|}
\hline Period & Acceptance \% & Hypothesis Ho \\
\hline Total10Yr & $\mathbf{8 6 . 1 5}$ & Accepted \\
\hline First5Yrsub-period & $\mathbf{8 9 . 5 4}$ & Accepted \\
\hline Second5Yrsub-period & $\mathbf{8 1 . 5 4}$ & Accepted \\
\hline First2.5Yrsub-period & $\mathbf{9 3 . 6 2}$ & Accepted \\
\hline Second2.5Yrsub-period & $\mathbf{9 0 . 2 0}$ & Accepted \\
\hline Third2.5Yrsub-period & $\mathbf{9 1 . 5 7}$ & Accepted \\
\hline Fourth2.5Yrsub-period & $\mathbf{9 6 . 4 1}$ & Accepted \\
\hline
\end{tabular}

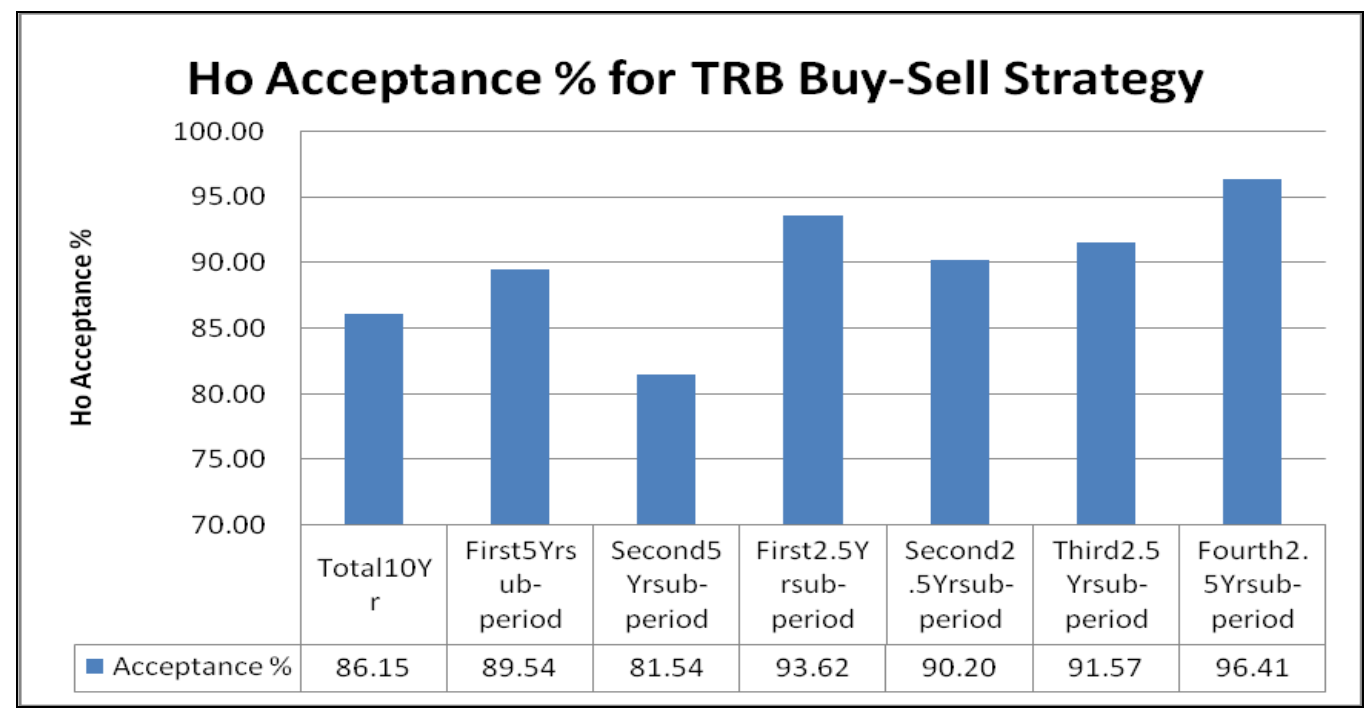

Fig3. Graphical sub-period Weekly TRB Buy-Sell Strategy test results

In case of TRB Buy-Sell strategy for all seven sub-periods the null hypothesis of weak form of market efficiency is accepted. The acceptance $\%$ is observed to be lowest in case of second 5 year sub-period.

The trading rule TRB test could not reject the null hypothesis Ho indicating the return series is weakform efficient. It means the weekly log returns of stocks accept hypothesis \{Random Walk No. 2 wherein $\varepsilon t \sim$ INID (independently and not identically distributed disturbance terms) $\}$ for all subperiods. The results of TRB test with 'Buy' strategy \& 'Sell' strategy exhibit lower level of predictability (i.e. more randomness) compared to 'Buy-Sell' strategy in all cases. Sub-period analysis reveals no substantial variation in the results.

The trading rule test of TRB accepts the hypothesis $\mathrm{H}_{0}$ for all three strategies of Buy, Sell \& Buy-Sell. This means trading rules in the Indian stock markets return series do not provide significantly different returns than buy \& hold strategy i.e. Indian stock markets return series of stocks is weakform efficient.

Results are contrary to earlier studies on trading rules viz. Balsara et al. (2007), Sundhar and Kakani (2006). The technical trading rules can be profitable to the extent to which the returns are just eliminated by the transaction costs that the trading rules incur under the version of market efficiency which is restated by Fama (1991). The earlier studies on technical analysis (Alexander, 1964, Fama and Blume, 1966) conclude that technical analysis is not profitable when transaction costs are taken into account. 
Prof. (Dr.) Uttam B. Sapate "Weak Form of Market Efficiency Trading Range Breakout Test on Weekly Stocks of India Markets"

\section{CONCLUSIONS}

The main findings of this study indicate the non-existence of TRB trading rule profitability in the Indian stock markets. The results from the trading rule tests indicated that the technical trading rules do not yield statistically significant forecasting power. It means that forecasting of returns based on trading rules cannot be employed to earn abnormal returns.

The results indicate that none of the trading rules exhibit statistically significant forecast power and trading rules (TRB) cannot produce economically significant returns relative to the buy and hold strategy. In spite of this it is observed that the trading rules normally are found to be appealing to the investors. The explanation for the same can be that these technical rules may be generating economic returns in certain time periods and may be dependent on selected type of stock.

\section{REFERENCES}

[1] Alexander, S. S. (1961), "Price movements in speculative markets: Trends or random walks", Industrial Management Review 2(2), 7-26.

[2] Balsara Nauzer J., Gary Chen, Lin Zheng. (2007), "The Chinese stock market: an examination of the random walk model and technical trading rules". Quarterly Journal of Business and Economics. University of Nebraska-Lincoln

[3] Brock, W., Lakonishok, J., \& Le Baron, B. (1992), "Simple technical trading rules and the stochastic properties of stock returns ”. Journal of Finance, Vol 47 (5), pp. 1731-1764.

[4] Fama, E. F. (1970), "Efficient Capital Markets: A Review of Theory and Empirical Work", Journal of Finance, Vol. 25, No. 2, pp. 383-417.

[5] Fama, E. F. (1991), "Efficient Capital Market: II”. Journal of Finance, vol. 5, 1575-1617.

[6] Fama, E. F. and Blume, M. (1966), "Filter Rules and Stock Market Trading Profiles". Journal of Business, vol. 39, 226-241.

[7] MATLAB - The Math Works, Inc. (2008), "MATLAB - The Language of Technical Computing". [online] Available at < http://www. mathworks.in/products/matlab/index.html >.

[8] Sundhar, S and Kakani, R. K. (2006). "Profiting from Technical Analysis in Indian Equity Markets: Using Moving Averages", XLRI Working Paper: 06-02, [Online] Available at SSRN: < http://ssrn.com/abstract=889515 >

[9] Thomas Lagoarde Segot \& Brian M Lucey, (2005), "Stock Market Predictability in the MENA: Evidence from New Variance Ratio Tests and Technical Trade Analysis", [online] Available at < http://ideas.repec.org/p/iis/dispap/iiisdp92.html>

\section{AUTHOR'S BIOGRAPHY}

Prof. (Dr.) Uttam B. Sapate, is presently working as a Professor of Finance and Operations at Marathwada Mitra Mandal's Institute of Management Education Research and Training (IMERT), Pune. $\mathrm{He}$ is a doctorate in Business Administration from AMU. His qualifications include BE (E\&T/C), GCOEP, Pune, M. Tech. (APE), IIT, Madras and MBA (Finance), JNTU, Hyderabad. He has 19 years of managerial experience from PSUs viz. HAL, IREDA and TCIL. For past nine tears he is in academics working with private management institutes from Pune in the capacity of approved Professor/Director from Pune University. His areas of interest are econometrics, operations research, stock markets etc. 